|| ISSN(online): 2589-8698 || ISSN(print): 2589-868X ||

International Journal of Medical and Biomedical Studies

Available Online at www.ijmbs.info

NLM (National Library of Medicine ID: 101738825)

Index Copernicus Value 2019: 79.34

Volume 5, Issue 1; January: 2021; Page No. 185-189

\title{
HISTOPATHOLOGICAL STUDY OF BENIGN AND MALIGNANT LESIONS OF UTERUS AND CERVIX IN
} HYSTERECTOMY SPECIMENS

\section{Dr. Shikha Raghuwanshi ${ }^{1}$ (PG Resident), Dr. Dharmendra Singh Bhadouria ${ }^{2}$ (PG Resident), Dr. Surendra Raghuwanshi $^{3}$ (DCH), Dr. Arun Saxena ${ }^{4}$ (Professor) \& Dr. S.K. Nema ${ }^{5}$ (HOD and Professor)}

Dept. of Pathology, Index Medical College Hospital and Research Centre, Indore M.P. ${ }^{1,2,3 \& \& 5}$

Article Info: Received 11 December 2020; Accepted 18 January 2021

DOI: https://doi.org/10.32553/ijmbs.v5i1.1666

Corresponding author: Dr. Arun Saxena

Conflict of interest: No conflict of interest.

\section{Abstract}

Background: The present study was aimed to obtain insight into the varied histopathological patterns of lesions of uterus and cervix in hysterectomy specimens and their age-wise distribution in Index MedicalCollege, Hospital and Research Center.

Methodology: This was anobservational study conducted on 100 cases of hysterectomy specimens received at tertiary care hospital Indore. All the specimen was subjected to detailed gross and histopathological examination.

Results: Mean age of patients was $44.78 \pm 8.64$ years. The most common age group was $41-50 \mathrm{yrs}(42 \%)$. Maximum cases were diagnosed as AUB/ DUB/Menorrhagia (31\%) followed by fibroid uterus (28\%). Uterus was bulky in 70\%, cut sections revealed single fibroid in majority i.e. $39 \%$ cases and endometrium was in proliferative phase (early $12 \%$, mid $30 \%$, late 19\%). Most common histopathological diagnosis of uterus was leiomyoma in $39 \%$ cases whereas chronic nonspecific cervicitis $(47 \%)$ was most common histological diagnosis of cervix. Intramural leiomyoma were most common and were associated with degenerative changes in 33 cases. Hyaline degeneration was observed in maximum cases.

Conclusion: The most common indication for hysterectomies in our institution is excessive uterine bleeding. Fibroid uterus as the cause of bleeding is the most common pathology for which hysterectomy is performed. Chronic cervicitis is the most common finding and Adenomyosis continued to be missed preoperatively and diagnosed postoperatively on histopathological examination. Every hysterectomy specimen should be subjected to histopathological examination to confirm various pathological lesions.

Keywords: Leiomyoma, histopathology, spectrum, uterus, cervix, hysterectomy

\section{Introduction}

The female genital tract is a hormone responsive system. Changes in uterus occur throughout life and prone to a variety of disorders, the most common of which results from hormonal imbalances, infections, tumours etc. ${ }^{[1]}$ On the global basis out of the first eight ranking cancers in females, cancers of the female reproductive system rank as follows- $1^{\text {st }}$ breast, $2^{\text {nd }}$ cervix, $7^{\text {th }}$ ovary and $8^{\text {th }}$ body of the uterus. The uterus is a vital reproductive organ and is subjected to many non-neoplastic and neoplastic conditions. ${ }^{[1]}$ Many treatment options are available including medical and conservative surgery but hysterectomy is the second most commonly performed gynecological surgery after cesarean section throughout the world. $^{[4]}$ Its indications vary from benign to malignant diseases. It is a definite treatment of fibroid, abnormal heavy bleeding, chronic pain, endometriosis, adenomyosis, uterine prolapse, pelvic inflammatory disease and carcinomas. ${ }^{[2]}$ It is done through an abdominal or vaginal route which may be associated with salpingoophorectomy of one or both sides. ${ }^{[4]}$

Uterine fibroids and adenomyosis are the most common benign conditions for hysterectomy at 40-50yrs. ${ }^{[4]}$ Most vaginal hysterectomies are done for uterine prolapse. ${ }^{[3]}$ Final diagnosis is only based on histology and due to this every hysterectomy specimens should be subjected to histopathological examination. Histopathological examinations have both diagnostic and therapeutic significance. ${ }^{[3]}$ The age wise and lesion wise incidence in patients undergoing hysterectomy is not readily available in our institution. So it is essential to study all cases of hysterectomy which are performed in Index Medical College \& Hospital, Indore. The present study aimed to obtain insight into the varied histopathological patterns of lesions of uterus and cervix in hysterectomy specimens and their age-wise distribution in our institution.

\section{Objectives}

- To analyze age wise incidence of lesions

- To study its correlation with respect to clinical manifestation.

\section{Methodology}

The present study was conducted as an observational study at 100 cases of hysterectomy specimens received at Department of Pathology, Index Medical College, Indorewhich were collected over a period of 2 years from July 2018 to April 2020.All the specimen of uterus with cervix obtained by total abdominal hysterectomy, vaginal hysterectomy or hysterectomy with bilateral salpingooophorectomy were included in the study. Following the receipt of surgical specimens in $10 \%$ formalin, a detailed 
gross examination and cut section morphology were recorded.

Then the specimens were allowed to fix in $10 \%$ formalin for 24-48 hours. The tissue bits from representative area were taken forhistopathological examination and paraffin blocks were prepared,routinely stained with haematoxylin and eosin stain. Finally associated microscopic lesions in the endometrium and cervix were observed and studied whenever present.

\section{Statistical analysis}

Data was compiled using MsExcel and analysed using IBM SPSS software version 20. Categorical data was expressed as frequency and percentage whereas numerical data was expressed as mean and standard deviation.

\section{Results}

The study included a total of 100 hysterectomy specimen belonging to females with age range of $44.78 \pm 8.64$ years. Maximum i.e. 56 cases ( $56 \%$ ) were operated as TAH with both adnexa preserved, 32 cases ( $32 \%$ ) as TAH with BSO, 8 cases $(8 \%)$ as TAH with USO and 4 cases ( $4 \%$ ) as vaginal route.

Table 1: Distribution of patients according to baseline variables

\begin{tabular}{|c|c|c|c|}
\hline \multicolumn{2}{|l|}{ Baseline variables } & \multirow{2}{*}{$\begin{array}{l}\text { No. } \\
4\end{array}$} & \multirow{2}{*}{$\begin{array}{l}\% \\
4.0\end{array}$} \\
\hline Age group & 21-30 years & & \\
\hline & $31-40$ years & 34 & 34.0 \\
\hline & $41-50$ years & 42 & 42.0 \\
\hline & $51-60$ years & 15 & 15.0 \\
\hline & $61-70$ years & 3 & 3.0 \\
\hline & $>70$ years & 2 & 2.0 \\
\hline \multirow[t]{2}{*}{ Parity } & Primi & 22 & 22.0 \\
\hline & Multi & 78 & 78.0 \\
\hline \multirow[t]{13}{*}{ Clinical diagnosis } & Fibroid uterus & 28 & 28.0 \\
\hline & AUB/DUB/Menorrhagia & 31 & 31.0 \\
\hline & UV Prolapse/ Procidentia/uterine prolapse & 13 & 13.0 \\
\hline & Adenomyosis & 7 & 7.0 \\
\hline & PID & 5 & 5.0 \\
\hline & Cervical erosion/polyp & 4 & 4.0 \\
\hline & Bulky Uterus & 3 & 3.0 \\
\hline & Adenomyosis with fibroid & 2 & 2.0 \\
\hline & Cystocoele & 2 & 2.0 \\
\hline & LSIL & 2 & 2.0 \\
\hline & DUB with Fibroid & 1 & 1.0 \\
\hline & Endocervical polyp & 1 & 1.0 \\
\hline & Endometrial hyperplasia with menorrhagia & 1 & 1.0 \\
\hline \multirow[t]{7}{*}{ Clinical features } & Menorrhagia & 31 & 31.0 \\
\hline & Abdominal pain with white discharge & 21 & 21.0 \\
\hline & Dysmenorrhea & 14 & 14.0 \\
\hline & Irregular menses & 9 & 9.0 \\
\hline & Polymenorrhea & 8 & 8.0 \\
\hline & Something coming out PV & 11 & 11.0 \\
\hline & Post menopausal bleeding & 6 & 6.0 \\
\hline
\end{tabular}

- Most common age group was 41-50yrs ( $42 \%$ ), followed by 34 cases ( $34 \%$ ) in age group 31-40yrs and least no. of cases were observed in more than 70 years of age $(2 \%)$.

- Maximum females were multiparous (78\%) whereas $22 \%$ were primiparous. Maximum cases were diagnosed as AUB/ DUB/Menorrhagia (31\%) followed by fibroid uterus (28\%), UV Prolapse/procidentia/uterine prolapse (13\%).

- Presenting complaint of maximum cases i.e 31 ( $31 \%$ )was menorrhagia followed by 21 cases ( $21 \%$ ) of abdominal pain, 14 cases ( $14 \%$ ) of dysmenorrhea, 8 cases $(8 \%)$ of polymenorrhea, 9 cases ( $9 \%$ ) of irregular menses, 11 cases $(11 \%)$ of something coming out PV,6 cases ( $6 \%$ ) of post menoupausal bleeding.

Table 2: Distribution according to Gross and histopathology of lesions

\begin{tabular}{|l|l|l|l|}
\hline \multicolumn{2}{|c|}{} & No. & \% \\
\hline Size of uterus & Bulky & 70 & 70.0 \\
\cline { 2 - 4 } & Normal & 22 & 22.0 \\
\cline { 2 - 4 } & Atrophic & 8 & 8.0 \\
\hline Cut section morphology & Unremarkable & 42 & 42.0 \\
\cline { 2 - 4 } & Single fibroid & 39 & 39.0 \\
\cline { 2 - 4 } & Multiple fibroid & 14 & 14.0 \\
\cline { 2 - 4 } & Cervical polyp & 4 & 4.0 \\
\cline { 2 - 4 } & Atrophic & 1 & 1.0 \\
\hline Type of endometrium & Early proliferative & 12 & 12.0 \\
\cline { 2 - 4 } & Mid proliferative & 30 & 30.0 \\
\cline { 2 - 4 } & Late proliferative & 19 & 19.0 \\
\cline { 2 - 4 } & Early secretory & 14 & 14.0 \\
\cline { 2 - 4 } & Mid secretory & 9 & 9.0 \\
\cline { 2 - 4 } & Late secretory & 6 & 6.0 \\
\cline { 2 - 4 } & Atrophic phase & 10 & 10.0 \\
\hline
\end{tabular}

- Uterus was seen bulky in 70 cases (70\%)

- Cut section morphology revealed single fibroid in majority i.e. $39 \%$ cases and multiple fibroids in $14 \%$ cases.

- Majority of endometrium were in proliferative phase (early $12 \%$, mid $30 \%$, late $19 \%$ ) followed by secretory phase ( early 14\%, mid 9\%, late 6\%), atrophic phase in $10 \%$. 


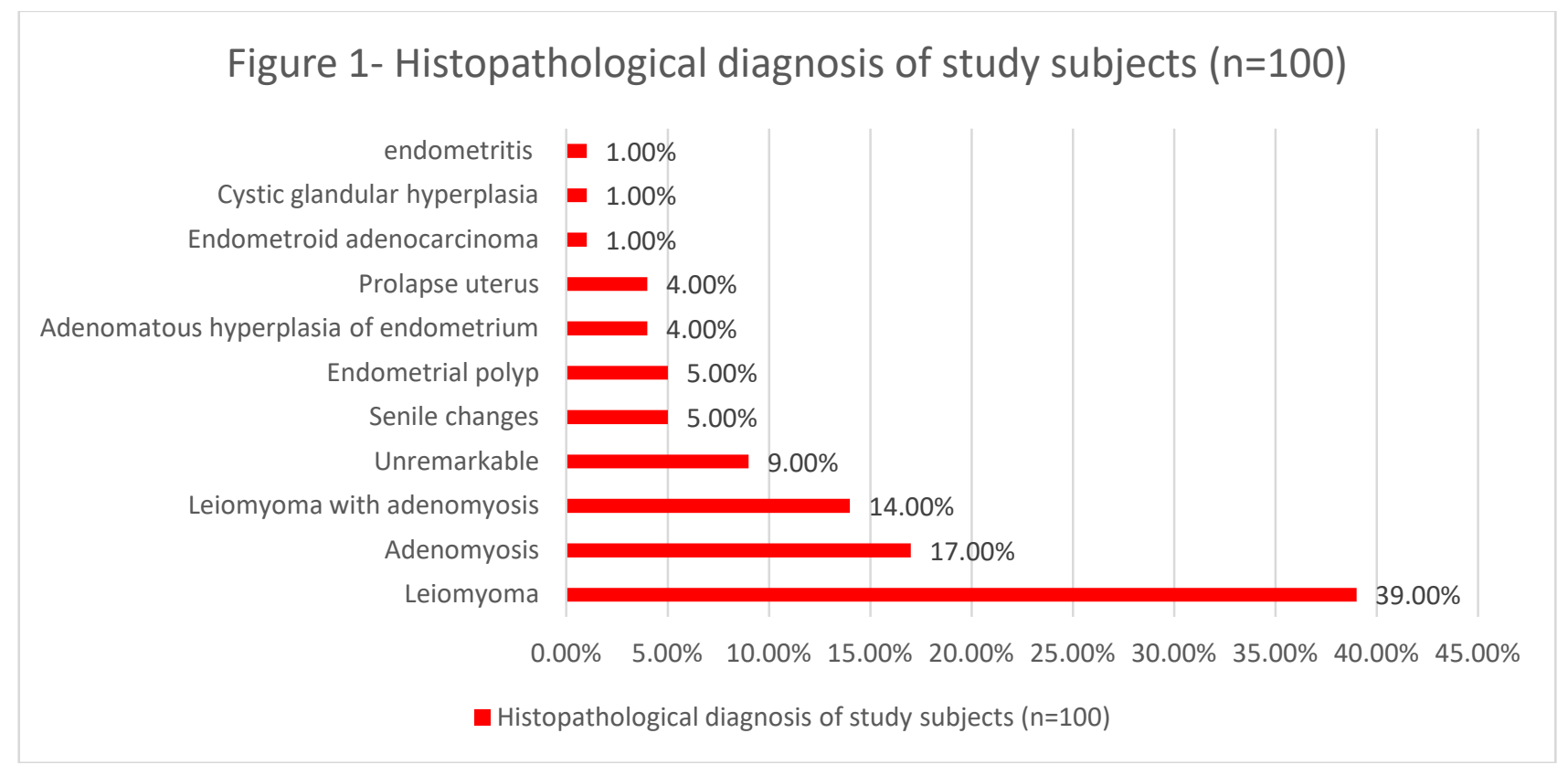

-39 cases $(39 \%)$ were diagnosed as leiomyoma

\section{Figure 1: reveals histopathological diagnosis of uterus}

-17 cases (17\%) as adenomyosis, 14 cases ( $14 \%$ ) as leiomyoma with adenomyosis

- 9 cases (9\%) as unremarkable, 5-5 cases ( 5\%) as senile changes and endometrial polyp 4-4 cases ( 4\% ) as adenomatous hyperplasia and prolapse,

- single cases as endometroid adenocarcinoma, cystic glandular hyperplasia and endometritis.

\section{Figure 2- Cervical finding in study subjects $(n=100)$}

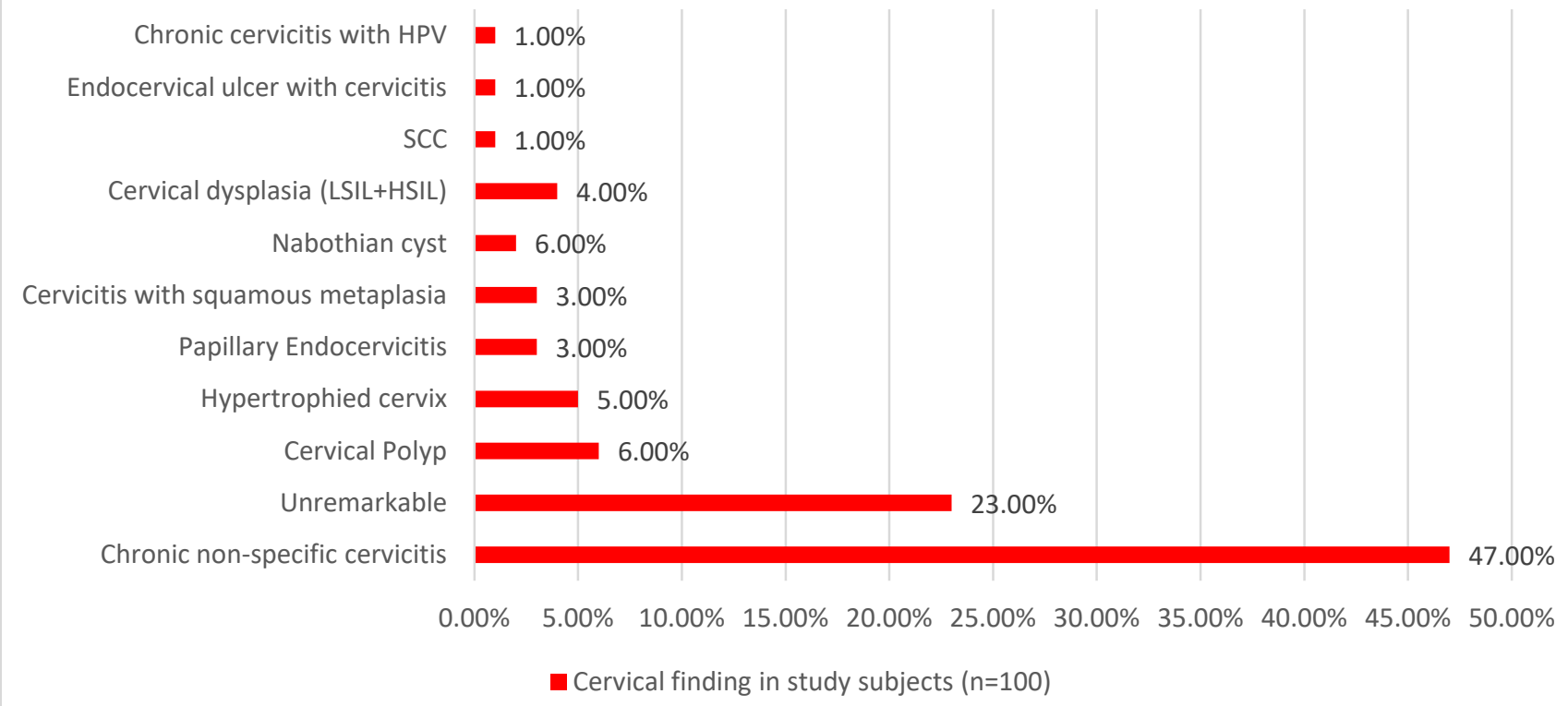

Figure 2: shows histopathological diagnosis of cervix

- Maximum cases were diagnosed as chronic nonspecific cervicitis as 47 cases ( $47 \%$ ), 23cases ( $23 \%$ ) as unremarkable, - 6 cases ( $6 \%$ ) as cervical polyp, 5 cases ( 5\%) as hypertrophied cervix, 3-3 cases ( $3 \%$ ) as papillary endocervicitis and cervicitis with squamous metaplasia,

- 4 cases ( $4 \%$ )of cervical dysplasia, 6 cases ( 6\% )as nabothian cyst and 1-1-1 cases as SCC, endocervical ulcer with cervicitis and chronic cervicitis with HPV. 
Table 3: Distribution according to characteristic of leiomyoma

\begin{tabular}{|c|c|c|c|}
\hline \multicolumn{2}{|l|}{ Leiomyoma } & No. $(n=55)$ & $\%$ \\
\hline \multirow[t]{4}{*}{ Location } & Intramural & 22 & 41.5 \\
\hline & Subserosal & 21 & 39.6 \\
\hline & Submucosal & 8 & 15.1 \\
\hline & Subserosal and intramural & 2 & 3.8 \\
\hline \multirow[t]{2}{*}{ Number } & Single & 39 & 73.6 \\
\hline & Multiple & 14 & 26.4 \\
\hline Histological type & Typical leiomyoma & 20 & 37.73 \\
\hline \multirow{7}{*}{$\begin{array}{l}\text { Degenerative changes } \\
(n=33)\end{array}$} & Hyaline degeneration & 17 & 51.5 \\
\hline & Red degeneration & 7 & 21.2 \\
\hline & Red and hyaline degeneration & 3 & 9.1 \\
\hline & Cystic degeneration & 2 & 6.1 \\
\hline & Calcification & 2 & 6.1 \\
\hline & Fatty change & 1 & 3.0 \\
\hline & Hyaline \&myxoid degeneration & 1 & 3.0 \\
\hline \multirow{6}{*}{ Type of endometrium } & Mid proliferative & 20 & 37.7 \\
\hline & Late proliferative & 11 & 20.7 \\
\hline & Early secretory & 6 & 11.3 \\
\hline & Mid secretory & 6 & 11.3 \\
\hline & Late secretory & 3 & 5.7 \\
\hline & Atrophic phase & 1 & 1.9 \\
\hline
\end{tabular}

- Majority cases $(41.5 \%)$ were diagnosed as intramural leiomyoma, 21 cases $(39.6 \%)$ as subserosal, 8 cases $(8 \%)$ as submucosal and both 2 cases ( $2 \%$ ) as subserosal and intramural.

- Single leiomyoma were seen in 39 cases $(73.6 \%)$ and multiple leiomyoma in 14 cases (26.4\%) Typical leiomyoma without any degenerative changes were observed in 20 cases $(37.73 \%)$ and in 33 cases $(62.26 \%)$, leiomyoma were associated with secondary changes.

- Among various degenerative changes, hyaline degeneration was observed in maximum cases. However, 37 cases were in proliferative phase, 15 cases in secretory phase and single in atrophic phase.

\section{Discussion}

Hysterectomy is the most commonly performedmajor gynecological procedure throughout the world. It is very successful in terms of symptom relief and patient satisfaction and provides definitive cure to many diseases.This was a two year study of 100 cases of hysterectomies. About $42 \%$ of hysterectomies were performed in the age group from 41-50 yrs, 34\% of hysterectomies in the age group 31-40 yrs and about $2 \%$ hysterectomies in more than 70yrs of age. Mean age of hysterectomy was $44.78+8.64$ yrs in our study which is similar to many studies like, Lodha ND et al ${ }^{[5]}$ in which majority of patients were in the age range of 41-50years $(41.5 \%)$, and the peak age group of hysterectomy was 41 $50 y r s$ ina study by Dhuliya $\mathrm{V}$ et al. ${ }^{[61]}$

Most gynecologistspreferred the abdominal route. In our Study, 96\% hysterectomies were done by this route in which total abdominal hysterectomies(TAH ) with both adnexa preserved were $(56 \%)$ andthrough vaginal route, hysterectomies were done very less $(4 \%)$ cases, which is in correlation with study of Saleh et $\mathrm{al}^{[7]}$. The abdominal route was used in 122 cases $(89 \%)$ and the vaginal route in 15 patients $(11 \%)$.Raza et $\mathrm{al}^{[8]}$ in their study showed that abdominal route was chosen in $74.3 \%$ (150/202) cases, while the vaginal route in $25.70 \%(52 / 202)$ cases.

Most common clinical diagnosis made by gynecologistin our studywas fibroid uterus i.e. (28\%) cases whereas $31 \%$ cases were reported to have AUB/DUB/Menorrhagia combined. Neelgund et al ${ }^{[9]}$ showed that leiomyoma was the dominant histopathological diagnosis in (22.4\%) cases. Baral et al ${ }^{[10]}$ found fibroid was the most common indication for hysterectomy which was seen in 229 $(42.94 \%)$ cases followed by uterovaginal prolapse in 101 $(18.93 \%)$ cases. In present study, most common presenting complaints was menorrhagia ( $31 \%$ ) followed by abdominal pain $(21 \%)$ and dysmenorrhea (14\%). Similarly, most common clinical indication for hysterectomy was menorrhagia followed by fibroid uterus in a study by Usha et al. $^{[11]}$ However, Raza et $\mathrm{al}^{[8]}$ inhis study showed that themenorrhagia was most common presenting complaint associated with leiomyoma and adenomyosis.

Bulky uterus was seen in maximum cases i.e.(70\%) cases, normal morphology was seen in (22\%) cases and atrophicuterus was seen in $(8 \%$ ) cases. Most common uterine lesions was leiomyoma seen in (39\%) cases, $(17 \%)$ cases of adenomyosis, (14\%) cases of leiomyoma with adenomyosis, $(6 \%)$ cases of senile changes and endometrial polyp, (4\%) cases of prolapse uterus and adenomatous hyperplasia of endometrium, $(1 \%$ )case of endometroid adenocarcinoma and cystic glandular hyperplasia and ( $9 \%$ ) cases were unremarkable. Similar findings were reported by Neelgund et al ${ }^{[9]}$ inwhich Leiomyoma ( $22.4 \%$ ) was the dominant histopathological diagnosis . Both adenomyosis 
and leiomyoma werepresent in $(6.4 \%)$ of the cases. Similarly, Dhuliya et $\mathrm{al}^{[6]}$ also noted leiomyomas (55 cases) as the most common pathology and next to it was adenomyosis.

In our study location of leiomyoma was intramural in $(41.5 \%)$, subserosal in $(39.6 \%)$, submucosal in $(8 \%)$, andsubserosal and intramural both in (2\%). Our study correlated well with the study of Dayal et $\mathrm{al}^{[12]}$ in which intramural fibroid $(75 \%)$ was most common. Single leiomyoma was seen in $(73.6 \%)$ and multiple in (26.4\%).Multiple leiomyomas when present were most common in intramural and subserosal location $(35.7 \%)$. Similarly Bhatta et $\mathrm{al}^{[13]}$ showed single leiomyoma in $(80.95 \%)$ and multiple in $(19.05 \%)$.

In our study, $62.3 \%$ of leiomyomas showed secondary degenerative changes. Various degenerative changes seen in leiomyoma were hyaline degeneration $(51.5 \%)$, then red degeneration in $(21.2 \%)$ and both seen in $(9.1 \%)$, cystic degeneration and calcification seen in $(6.1 \%)$, fatty change and myxoid degeneration seen in $(3 \%)$. Bhatta et al ${ }^{[13]}$ showed hyaline degeneration whichoccurred most frequently $(7.14 \%)$, followed by calcification in $(1.78 \%)$, myxoid degeneration in $(1.2 \%)$, hydropic degeneration in $(0.6 \%)$ cases. Cut section morphology showed that most of them were unremarkable in (42\%), single fibroid present in (39\%), multiple fibroid in (14\%), cervical polyp in $(4 \%)$ and $(1 \%)$ was atrophic. Microscopic findings of cervix showed that most common lesion was chronic nonspecific cervicitis in $(47 \%)$, cervical polyp in $(6 \%)$, hypertrophied cervix in $(5 \%)$, papillary endocervicitis and cervicitis with squamous metaplasia seen in $(3 \%)$ each, cervical dysplasia (LSIL and HSIL) in (4\%) and nabothian cysts seen in (6\%), SCC, endocervicitis with erosion, chronic cervicitis with HPV in (1\%) each and unremarkable was in $(23 \%)$. Our study correlated well with Lodha ND et al[5]. Cervical pathology included majority of the cases i.e. $318(81.96 \%)$ of chronic cervicitis followed by $54(13.92 \%)$ cases of squamous metaplasia, $1(0.26 \%)$ case of tubal metaplasia and $2(0.52 \%)$ cases of acute cervicitis. Endocervical polyp was seen in $3(0.77 \%)$ cases followed by papillary endocervicitis. Another study by Krishna et $\mathrm{al}^{[14]}$ showed chronic nonspecific cervicitis seen in 181 cases which was associated with nabothian cyst and squamous metaplasia. Chronic nonspecific cervicitis $(70 \%)$ was reported in the study of Jain et al. ${ }^{[15]}$

\section{Conclusion}

The most common indication for hysterectomies in our institution is excessive uterine bleeding. Fibroid uterus as the cause of bleeding is the most common pathology for which hysterectomy is performed. Chronic cervicitis is the most common finding and Adenomyosis continued to be missed preoperatively and diagnosed postoperatively on histopathological examination. Every hysterectomy specimen should be subjected to histopathological examination to confirm various pathological lesions.

\section{References}

1. Samaila Modupeola OA, Adesiyun AG, Agunbiade OA, Mohammed-Duro A. Clinico-pathological assessment of hysterectomies in Zaria. European Journal of General Medicine. 2009;6(3):150-3

2. Nausheen F, Iqbal J, Bhatti FA, Khan AT, Sheikh S. Hysterectomy: The patients perspective. Annals of King Edward Medical University. 2004;10(4).

3. Silverberg SG, De Lellis RA, Frable WJ, Li Volsi VA, Wick MR. Neoplastic diseases of the small and large intestines. Silverberg's Principles and Practice of Surgical Pathology and Cytopathology. 2006;2:1419-64.

4. Sobande AA, Eskander M, Archibong EI, Damole IO. Elective hysterectomy: A clinicopathogical review from Abha catchment area of Saudi Arabia. West African journal of medicine. 2005 May 13;24(1):31-5.

5. Lodha ND, Bhart KS. Evaluation of Histopathological Lesions in Hysterectomy Specimens at a Tertiary Care Center International Journal of Biomedical Research 2018; 09(09): 335-7.

6. Dhuliya V, Gosai D. Histopathological Study of Specimens. BJKines-NJBAS. 2016 8(2) 23-6.

7. Saleh SS, Fram K. Histopathology diagnosis in women who underwent a hysterectomy for a benign condition. Archives of gynecology and obstetrics. 2012 May 1;285(5):1339-43.

8. Raza AM, Nahar M, Islam MR. Patterns of Lesion in Hysterectomy Specimen, Experience of Two Years in a Medical College Hospital. 2017;2[1];12-16.

9. Neelgund S, Hiremath P. Analytical study of hysterectomies. Int J Reprod Contracept Obstet Gynecol. 2016;5(7):2307-11.

10. Baral R, Pudasaini S. Histopathological pattern of endometrial samples in abnormal uterine bleeding. Journal of Pathology of Nepal. 2011;1:13-6.

11. Usha S, Lulla M, Gupta P, Sirsat L, Garud M, Sociodemographic profile of women with cancer, dysplasia, control group.Journal of obs and gyn 1983;33;379-80.

12. Dayal S, Kumar A, Verma A. Clinicopathologic correlation of leiomyoma with clinical findings and secondary changes in a rural population of north India. American journal of clinical pathology. 2014 Feb 1;141(2):275-9.

13. Bhatta S, Bhandari S, Osti BP. Histopathological study of Uterine Leiomyoma in Hysterectomy Specimens. Annals of Clinical Chemistry and Laboratory Medicine. 2017;3(2):1620.

14. Krishna T, Gattu V. Study of spectrum of lesions of cervix in hysterectomy specimens. 2017;5[4c];1443-9.

15. Jain A, Dhar R, Patro P, Sahu S. Histopathological study of cervical lesions. Int J Health Sci Res. 2018; 8(11):82-7. 